\title{
Changes in the tissues of guinea-pigs fed on a diet free from vitamin $A$ but containing methyl retinoate
}

\author{
By J. McC. HOWELL, \\ Department of Veterinary Pathology, \\ AND J. N. THOMPSON, \\ Department of Biochemistry, University of Liverpool, \\ AND G. A. J. PITT, \\ Department of Animal Science, University of Illinois
}

(Received I3 April I966-Accepted I5 August I966)

1. Forty-eight guinea-pigs were fed from weaning on a semi-synthetic diet free of retinol and carotenoids. Twenty-two of these animals received a twice-weekly supplement of methyl retinoate and fifteen received a twice-weekly supplement of retinyl acetate. The remaining eleven animals were fed on the vitamin A-free diet without supplementation.

2. At varying times throughout the experiment, animals died or were killed by chloroform inhalation. Testes and seminal vesicles were weighed and these tissues together with trachea, lungs, salivary glands, bladder, eyes and vagina were examined histologically.

3. The eleven guinea-pigs that received the unsupplemented diet developed signs of vitamin A deficiency after being fed on the diet for 3 or 4 weeks. Many epithelia showed a metaplastic change to the stratified squamous form often with keratinization.

4. The guinea-pigs given supplements of either methyl retinoate or retinyl acetate grew at a normal rate and developed none of the signs of vitamin A deficiency that appeared in the animals on the unsupplemented diet. Evidence of metaplastic change in epithelia was not seen in any of these animals.

5. Thirteen males were fed on the deficient diet and methyl retinoate. The testicles and seminal vesicles of these animals weighed less than those of the ten males fed on the deficient diet and retinyl acetate. The testes of the former showed severe histological degeneration of the seminiferous epithelium. The testes of the guinea-pigs fed on retinyl acetate were normal.

6. Fifteen guinea-pigs fed on the deficient diet and retinyl acetate were mated to normal males. Eleven were thought to have become pregant. Eight of these gave birth to twenty-four pups. One died in advanced pregnancy with five apparently normal pups in utero and one produced three living young and died with one still in utero. Sixteen guinea-pigs fed on the deficient diet and methyl retinoate were mated to normal males. Twelve were thought to have conceived but all resorbed their foetuses.

7. The vision of guinea-pigs fed on the synthetic diet and methyl retinoate deteriorated progressively, and after I 50 days on the experiment the pupils did not respond to light. However, degeneration of the retina, such as had been seen in rats fed on a vitamin A-deficient diet containing methyl retinoate, was not seen in any of the guinea-pigs.

In the rat, retinoic acid has been found to replace retinol in all its functions other than in vision (Dowling \& Wald, I960) and reproduction (Thompson, Howell \& Pitt, I964). Rats maintained on a diet deficient in retinol but containing retinoic acid grow well and appear healthy, but are blind, their seminiferous epithelium degenerates (Howell, Thompson \& Pitt, 1963), and although females become pregnant they resorb their foetuses (Howell, Thompson \& Pitt, I964).

The failure of retinoic acid to maintain vision results from the inability of animals to utilize it as a precursor of retinal, the prosthetic group of the visual pigments (Moore, 
1953; Dowling \& Wald, I96o). Its failure to maintain reproduction in rats has as yet no comparably explicit biochemical basis. In this species and perhaps others, retinol may have a special reproductive function (Thompson, Howell \& Pitt, I965).

Domestic fowl fed on a retinol-free diet containing retionoic acid also grow well, appear healthy but become blind. The seminiferous epithelium of cocks develops normally and the semen will successfully fertilize the eggs of normal hens. Hens maintained on the basal retinol-free diet with a retinoic acid supplement lay eggs at a normal rate, and although such eggs can be fertilized, the development of the embryos ceases at an early stage of incubation (Thompson, Howell, Pitt $\&$ Houghton, 1965).

Because of the differences between the biological activity of retinoic acid in retinoldeprived rats and poultry it seemed desirable that retinoic acid should be tested biologically in other species. The present paper presents our observations on guineapigs which were made completely deficient in vitamin $A$ or were maintained for long periods on a vitamin A-deficient diet supplemented with either retinoic acid or retinyl acetate.

\section{EXPERIMENTAL}

Animals and diet. Albino guinea-pigs were bought as weanlings and were given from the onset a semi-synthetic diet free from retinol and carotenoids (Table $r$ ). This diet was based on results published by Reid (1963).

Forty-eight guinea-pigs weighing approximately $200 \mathrm{~g}$ were divided into three groups, each containing animals of both sexes. Twenty-two animals received, by

\begin{tabular}{lc}
\multicolumn{1}{c}{ Table I. Composition of the vitamin } & $\begin{array}{c}\text { A-free diet } \\
\text { Component }\end{array}$ \\
& $\begin{array}{c}\text { Amount } \\
(\%)\end{array}$ \\
& $20 \cdot 0$ \\
Extracted casein (Genatosan Ltd) & $1 \cdot 0$ \\
Arginine hydrochloride & $0 \cdot 5$ \\
Methionine & $20 \cdot 0$ \\
Starch & $6 \cdot 0$ \\
Glucose & $15 \cdot 3$ \\
Sucrose & $5 \cdot 0$ \\
Dried brewer's yeast & $15 \cdot 0$ \\
Cellulose powder & $6 \cdot 0$ \\
Arachis oil & $6 \cdot 0$ \\
Salts* & $2 \cdot 5$ \\
Potassium acetate & $0 \cdot 5$ \\
Magnesium oxide & $0 \cdot 2$ \\
Choline chloride & $1 \cdot 0$ \\
Vitamin mixture in glucose $\dagger$ & $1 \cdot 0$ \\
Vitamin mixture in arachis oil $\downarrow$ & See below\$ \\
Ascorbic acid &
\end{tabular}

* Salts $\mathrm{N}$ of Fox \& Briggs (1960) supplemented with the following trace minerals (g/6o kg salts): $\mathrm{Na}_{2} \mathrm{SeO}_{3} 0 \cdot 2, \mathrm{NaF} 0 \cdot 5, \mathrm{CoCl}_{2} .6 \mathrm{H}_{2} \mathrm{O} 2 \cdot 0, \mathrm{Na}_{2} \mathrm{MoO}_{4} \cdot 2 \mathrm{H}_{2} \mathrm{O} 5 \cdot 0, \mathrm{H}_{3} \mathrm{BO}_{3}$ I0.0, $\mathrm{K}_{2} \mathrm{Al}_{2}\left(\mathrm{SO}_{4}\right)_{4} \cdot 24 \mathrm{H}_{2} \mathrm{O}$ 5, $\mathrm{Ns}_{2} \mathrm{SiO}_{3} \cdot 9 \mathrm{H}_{2} \mathrm{O}$ \%.

$\dagger$ Contained (per $100 \mathrm{~g}$ ): nicotinic acid $\mathrm{I} \mathrm{g}$, thiamine hydrochloride $240 \mathrm{mg}$, calcium pantothenate $200 \mathrm{mg}$, riboflavine $160 \mathrm{mg}, p$-aminobenzoic acid $80 \mathrm{mg}$, pyridoxine hydrochloride $80 \mathrm{mg}$, folic acid $40 \mathrm{mg}$, menaphthone ro $\mathrm{mg}$, biotin $3 \mathrm{mg}$, cyanocobalamin $300 \mu \mathrm{g}$.

I Contained (mg/roo g): DL- $\alpha$ tocopheryl acetate 200, cholecalciferol 0.2 .

$\S$ Each animal was given by pipette on alternate days $0.5 \mathrm{~g}$ ascorbic acid in $\mathrm{x} \mathrm{ml} 20 \%(\mathrm{w} / \mathrm{v})$ sucrose solution. 
pipette, a twice-weekly supplement of methyl retinoate $(0.5 \mathrm{mg} /$ animal $)$ dissolved in oil, fifteen were given in a similar fashion twice-weekly supplements of retinyl acetate $(0.5 \mathrm{mg} / \mathrm{animal})$ and the remaining eleven animals were fed on the vitamin $\mathrm{A}$-free diet without supplementation.

Mating of females. In the first experiments, two groups of female guinea-pigs, seven given methyl retinoate and five given retinyl acetate, were each placed with a normal male and subsequent pregnancies and resorptions were recognized by changes in body-weight and vaginal bleeding. In the later experiments, in which nine guineapigs given methyl retinoate and ten given retinyl acetate were used, each female was caged with one normal male until a copulation plug was found at the bottom of the cage, indicating the time of mating. The male was then taken away and the female left in its cage until the termination of pregnancy.

Histological examination of tissues. Animals died, or were killed by chloroform inhalation, after varying periods on the experiment. Tissues, excepting eyes, were fixed in Bouin's fluid and were embedded in paraffin wax; sections cut at $5 \mu \mathrm{m}$ were stained by haematoxylin (Mayer's haemalum) and eosin, and where appropriate by the periodic acid-Schiff technique. Eyes were removed as quickly as possible after death and were fixed in Zenker's fluid; they were subsequently embedded in low viscosity nitrocellulose and sections cut at $12 \mu \mathrm{m}$ were stained by haematoxylin and eosin.

\section{RESULTS}

\section{Signs of vitamin A deficiency}

Eleven guinea-pigs (six males and five females) were given the basal diet without supplements of either methyl retinoate or retinyl acetate. All these animals developed signs of vitamin A deficiency, i.e. loss of body-weight, dryness of the cornea, matted eyelids and dyspnoea, after 3 or 4 weeks on the basal diet.

Table 2. Changes in the epithelia of guinea-pigs fed on the synthetic diet which was deficient in vitamin $A$

The diet was given at weaning-body-weight approximately $200 \mathrm{~g}$

\begin{tabular}{|c|c|c|c|c|c|c|c|c|}
\hline \multirow[b]{2}{*}{$\begin{array}{l}\text { No of days } \\
\text { on diet }\end{array}$} & \multirow[b]{2}{*}{ Sex } & & \multicolumn{6}{|c|}{ Changes in epithelia } \\
\hline & & $\begin{array}{l}\text { Died or } \\
\text { killed }\end{array}$ & $\begin{array}{l}\text { Submaxilla } \\
\text { salivary } \\
\text { gland }\end{array}$ & Bladder & Trachea & Lung & Vagina & $\begin{array}{l}\text { Seminal } \\
\text { vesicles }\end{array}$ \\
\hline 22 & $\delta$ & Died & $\mathrm{N}$ & $\mathbf{N}$ & $\mathbf{N}$ & $\mathrm{N}^{*}$ & - & - \\
\hline 28 & q & Died & $\mathbf{S}$ & $\mathbf{N}$ & S & $\mathbf{N}^{*}$ & $\mathbf{S}$ & - \\
\hline 34 & $\sigma^{\prime \prime}$ & Died & SK & $\mathbf{N}$ & $S$ & $\mathbf{N}^{*}$ & - & 一 \\
\hline 39 & 우 & Died & SK & SK & SK & $\mathbf{N}^{*}$ & SK & - \\
\hline 42 & 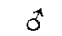 & Died & SK & $\mathrm{SK}$ & $\mathrm{S}$ & $\mathbf{N}^{*}$ & - & - \\
\hline 42 & P & Died & SK & $\mathrm{S}$ & $S$ & $\mathbf{N}^{*}$ & SK & - \\
\hline 43 & $\theta$ & Died & SK & SK & SK & $\mathrm{N}^{*}$ & - & $\mathrm{N}$ \\
\hline 45 & $\sigma^{*}$ & Died & SK & $\mathbf{N}$ & $\mathrm{S}$ & $\mathbf{N}^{*}$ & - & $\mathbf{N}$ \\
\hline 47 & 9 & Killed & SK & SK & SK & N* & SK & - \\
\hline 47 & $\partial$ & Died & SK & $\mathrm{N}$ & $\mathrm{S}$ & $\mathrm{N}$ & - & $\mathbf{N}$ \\
\hline 54 & q & Died & $\mathrm{S}$ & $\mathrm{S}$ & SK & $\mathrm{N}^{*}$ & $\mathbf{N}$ & - \\
\hline
\end{tabular}

$\mathrm{N}$, no metaplastic change; $\mathrm{S}$, metaplasia to stratified squamous epithelium (Pl. $2 c$ ); SK, metaplasia to stratified squamous epithelium with keratinization (P1. $2 d$ ). *, Animal developed pneumonia. 
The results of the histological examination of the tissues from these animals are given in Table 2, and see Pl. $2 c$ and $d$. Many epithelia showed a metaplastic change to the stratified squamous form often with keratinization.

\section{Effects of supplements of retinyl acetate and methyl retinoate}

Growth and epithelia. The guinea-pigs given supplements of either methyl retinoate or retinyl acetate grew at a normal rate and developed none of the overt signs of vitamin A deficiency that were so marked in the animals on the unsupplemented diet. The trachea, lungs and salivary glands from fifteen guinea-pigs given methyl retinoate, and the bladder from fourteen of these animals, were examined for macroscopic and histological changes. Trachea, lungs, salivary glands and bladder were similarly examined from ten guinea-pigs given retinyl acetate. Two of the animals given methyl retinoate were females and they were killed after 22 and 38 days on the diet. Details of the male guinea-pigs used are given in Table 3. Seven of the animals in each of these groups had pneumonia. Evidence of epithelial metaplasia to a keratinizing stratified squamous form was not seen in any of the sections.

Table 3. Details of the guinea-pigs given the synthetic diet supplemented with either methyl retinoate or with retinyl acetate

These diets were given from weaning-body-weight approximately $200 \mathrm{~g}$

Synthetic diet and methyl retinoate

No. of da
on diet
28
48
57
72
$76^{*}$
97
$150^{*}$
$150^{*}$
$179^{*}$
$207^{*}$
$267^{*}$
$267^{*}$
$339^{*}$
$460^{*}$

Synthetic diet and retinyl acetate

\begin{tabular}{|c|c|c|}
\hline $\begin{array}{l}\text { No. of days } \\
\text { on diet }\end{array}$ & $\begin{array}{l}\text { Weight of } \\
\text { testes }(g)\end{array}$ & $\begin{array}{l}\text { Weight of } \\
\text { seminal } \\
\text { vesicles (g) }\end{array}$ \\
\hline 28 & $0.371,0.347$ & 0.483 \\
\hline 48 & $0.848,0.8 \mathrm{I}_{3}$ & $I \cdot 06 \mathrm{I}$ \\
\hline 57 & 0.8 I $_{4}, 0.7 \mathrm{I}_{3}$ & $\mathrm{I} \cdot 098$ \\
\hline 72 & $I \cdot I 55, I \cdot 069$ & $2 \cdot 36 I$ \\
\hline $76 *$ & I.099, 0.723 & $1 \cdot 252$ \\
\hline 97 & $I \cdot 522, I \cdot 310$ & $2 \cdot 603$ \\
\hline I50* & $2 \cdot 283,2 \cdot 4 I_{3}$ & $5 \cdot 35^{8}$ \\
\hline - & $-\quad-$ & - \\
\hline- & $-\quad-$ & - \\
\hline $207^{*}$ & $I \cdot 934,2 \cdot 008$ & 4772 \\
\hline - & - - & 一 \\
\hline - & - - & - \\
\hline $339^{*}$ & $I \cdot 824, r \cdot 952$ & 4.552 \\
\hline $460 *$ & I' $999,2 \cdot 028$ & $5.93 I$ \\
\hline
\end{tabular}

The male reproductive tract. The testes of the guinea-pigs maintained with retinoic acid were found to be smaller than those of guinea-pigs of the same age that had been given retinyl acetate (see Table 3 ).

The testes of eight of the ten guinea-pigs that had received retinyl acetate had a normal mature seminiferous epithelium (Pl. $\mathrm{I} a$ ) and the epididymal duct in these animals contained a large number of spermatozoa (P1. $\mathrm{r} b$ ). The testes of the two other guinea-pigs were immature; these animals had been on the diet for only 28 days and 48 days respectively, and spermatozoa were present in the epididymal duct of the latter guinea-pig. 
None of the testes from the animals given the basal deficient diet and methyl retinoate were normal: all showed degenerative changes in the seminiferous epithelium. A few spermatids with well-developed heads and tails were observed in the testes of the animals that were examined after 57 and 72 days on the diet (Table 3), but in these animals most tubules had a degenerated seminiferous epithelium which in some was reduced to Sertoli cells and a few spermatogonia. The tubules in the testes of the nine guinea-pigs examined after they had been fed on the diet for longer than 72 days were lined only by Sertoli cells and spermatogonia, and few spermatocytes were present; many of the tubules did not have a lumen (Pl. I c ). The epididymal ducts in these animals were either empty or contained eosinophilic material and cellular debris (Pl. I $d$ ).

The interstitial cells in the testes of the animals given methyl retinoate showed no sign of degeneration, but on the contrary in many sections they appeared to be present in larger numbers $(\mathrm{Pl} . \mathrm{I} c)$ than were observed in controls $(\mathrm{Pl}$. I $a)$. However, the testes of the guinea-pigs that were given methyl retinoate were smaller than those of control animals and the apparent increase in interstitial cells may have been due to the packing of a similar number of cells into a smaller space.

The weights of the seminal vesicles of thirteen guinea-pigs given methyl retinoate and ten that had been given retinyl acetate are listed in Table 3 . The seminal vesicles were found to be smaller in the guinea-pigs given methyl retinoate than in those given retinyl acetate, but this difference was far less marked in the older animals, and was not apparent in guinea-pigs that were examined after 300 days on the diet. Histologically the seminal vesicles from the two groups of animals were identical and normal; there was no indication of a metaplastic change in the epithelium.

Reproduction in the female. In one experiment, normal male guinea-pigs were caged with a group of seven female guinea-pigs maintained with methyl retinoate and a group of five female guinea-pigs maintained with retinyl acetate for a period of I2 weeks. The males given the methyl retinoate-supplemented diet were dosed individually with retinyl acetate. Two litters comprising a total of five pups were obtained from the guinea-pigs given retinyl acetate; one animal in this group which died was found to have five well-developed foetuses in the uterus, and another guineapig in this group showed signs of foetal resorption in that it increased in weight, bled from the vagina and then decreased in weight.

Among the animals given methyl retinoate, six showed an initial increase in weight: five of these bled from the vagina and several necrotic placental remnants were found on the floor of the cage. Litters were not born to this group of animals.

In a second experiment nine female guinea-pigs given methyl retinoate and ten given retinyl acetate were placed individually with normal males until copulation plugs were found in the cages. Of the eight guinea-pigs given retinyl acetate which mated, only one subsequently failed to show any indications of pregnancy, and the remaining seven all delivered litters containing a total of twenty-two pups. After seven matings in the guinea-pigs given methyl retinoate, body-weight increases occurred and in four instances vaginal bleeding was observed during the $3^{\text {rd }}$ week after mating and dlacental remnants were discharged. No litters were born in this group of animals. 
Vision. The vision of guinea-pigs given methyl retinoate showed signs of progressive deterioration during the experiment. After Ioo days on the diet, constriction of the pupil in response to bright light was noticeably less in the guinea-pigs given methyl retinoate than in the controls given retinyl acetate. By the time the animals had been on the diet for 150 days the pupils of the eyes of the guinea-pigs given methyl retinoate remained widely dilated even in daylight or when bright lights were shone directly into the eye. At that stage the animals clearly had severely impaired vision.

Retinas from nine guinea-pigs given methyl retinoate and five that had been given retinyl acetate were examined histologically. These animals had been on the experiment for periods ranging from 67 to 460 days (Table 3 ). Degeneration of the retina was not detected in any of the eyes examined (Pl. $2 a$ and $b$ ).

\section{DISCUSSION}

In the guinea-pigs fed on the basal diet without supplements of either retinyl acetate or methyl retinoate, the abnormalities, i.e. loss of weight and squamous metaplasia of epithelia, were typical of vitamin A deficiency in the guinea-pig (Wolbach \& Howe, 1928). As these lesions were not observed in animals given supplements of retinyl acetate, it can be concluded that the major and probably sole deficiency in the basal diet was of vitamin A.

The guinea-pigs given the unsupplemented diet showed signs of vitamin A deficiency during the ist month of the experiment. This period represents the time taken to exhaust the stores of vitamin A acquired before birth and during lactation. Beyond that stage the animals in the other groups were entirely dependent on their intake of retinyl acetate or methyl retinoate.

It was found that supplements of methyl retinoate were qualitatively as effective as supplements of retinyl acetate in preventing the overt signs of deficiency that occurred in the animals given a vitamin A-free diet. In the guinea-pig, therefore, as in the rat (Arens \& van Dorp, I946; Dowling \& Wald, 1960; Thompson et al. 1964) and domestic fowl (Thompson, Howell, Pitt \& Houghton, 1965), retinoic acid maintains growth and general health. A number of these guinea-pigs developed pneumonia, but unfortunately pneumonia is prevalent in our stock colony. Histological examination of trachea, lung, submaxillary salivary gland and bladder from guinea-pigs maintained with methyl retinoate did not reveal any evidence of metaplastic changes in epithelial tissues. These animals had a healthy appearance and normal body-weight throughout the experiment, even though some were maintained on the methyl retinoate diet for over a year. These findings showed conclusively that retinoic acid was effectively replacing the true vitamin in its general 'systemic' roles (see Thompson et al. 1964).

In male guinea-pigs, methyl retinoate did not meet the needs of the testes: in guinea-pigs maintained with methyl retinoate degenerative changes occurred in the seminiferous epithelium and eventually most of the germinal cells were lost. Histologically and macroscopically, the lesion was similar to that observed previously in male rats (Howell et al. 1963 ) and thus the failure of retinoic acid to support the germinal epithelium of the testes in both rats and guinea-pigs contrasts with the finding that 
cocks fed on a retinol-free diet and retinoic acid have normal testes and produce normal sperm (Thompson, Howell, Pitt \& Houghton, I965).

Female guinea-pigs given the basal vitamin A-free diet plus methyl retinoate mated with normal males but subsequently resorbed their foetuses and did not deliver litters. Thus, although it was not possible to investigate the changes in the guinea-pig as extensively as in the rat (Howell et al. 1964), it appears that in both species retinoic acid does not sustain the later stages of pregnancy. In the guinea-pig and in the rat supplements of retinyl acetate prevented the disorders of reproduction found in males and females given retinoic acid, suggesting that, in mammals generally, retinol is an important fertility factor (Thompson, Howell \& Pitt, I965).

Dowling \& Wald (I960) found that, in albino rats fed on a vitamin A-free diet with added retinoic acid, the visual threshold, as measured by the external electroretinogram, increased markedly as the animals lost their stores of the true vitamin. This change was associated with a fall in the rhodopsin content of the eye followed by loss of the visual protein, opsin, and histological breakdown of the entire rod-cone layer. We have since confirmed similar electrophysiological and histological lesions in hooded rats fed our retinoic acid diet (W. A. Coward, J. McC. Howell \& J. N. Thompson, in preparation), although the development of the changes was not as rapid as in the experiments of Dowling \& Wald (ig60).

Although guinea-pigs given the retinoic acid supplement became blind, as was clearly shown by their behaviour and dilated pupils, retinal degeneration was not found even though some of these animals were maintained on methyl retinoate for over a year. This is more than twice the time needed to produce severe anatomical changes in the retinas of rats on the same diet. The guinea-pig retina, although similar to that of the rat in that it contains mainly rods with some cones (O'Day, r947), responded in our experiment more closely to that of the predominantly cone retina of the fowl (Thompson, Howell, Pitt \& Houghton, 1965).

The variation in the stability of the retinal structures in various species may be related to differences in the stability of opsins in vitro. Rat opsin in digitonin suspension will not regenerate visual pigment (Dowling \& Wald, 1958), whereas we have found that guinea-pig opsin can be extracted with digitonin from completely bleached retinas of normal guinea-pigs and will readily reform rhodopsin on addition of retinal. Dowling $\&$ Wald ( 1958, I960) suggested that opsin was unstable in vivo when not combined with its prosthetic group and that the structural integrity of rods and cones thus depended on the availability of retinal. Though this appears to be true for the rat, it does not seem to apply to the guinea-pig or fowl.

We thank Professor D. L. Hughes and Professor R. A. Morton, FRS, for encouragement and advice, Mrs M. W. Harling, AIMLT, and Mrs C. McLaughlin for technical assistance, and Mr G. Weston, FIMLT, and Mr E. O'Neill for the photographs. Dr O. Isler of F. Hoffmann-La Roche and Co., Basle, made generous gifts of retinoic acid. 


\section{REFERENCES}

Arens, J. F. \& van Dorp, D. A. (I946). Nature, Lond. 157, 190.

Dowling, J. E. \& Wald, G. (1958). Proc. natn, Acad. Sci. U.S.A. 44, 648.

Dowling, J. E. \& Wald, G. (1960). Proc. natn. Acad. Sci. U.S.A. 46, 587.

Fox, M. R. S. \& Briggs, G. M. (1960). F. Nutr. 72, 243.

Howell, J. McC., Thompson, J. N. \& Pitt, G. A. J. (1963). F. Reprod. Fert. 5, r 59.

Howell, J. McC., Thompson, J. N. \& Pitt, G. A. J. (I964). F. Reprod. Fert. 7, 25 I.

Moore, T. (1953). In Symposium on Nutrition, p. 28. [R. M. Herriott, editor.] Baltimore: Johns Hopkins Press.

O'Day, K. (1947). Nature, Lond. 160, 648.

Reid, M. E. (1963). F. Nutr. 8o, 33 .

Thompson, J. N., Howell, J. McC \& Pitt, G. A. J. (1964). Proc. R. Soc. B r59, 5 Io.

Thompson, J. N., Howell, J. McC. \& Pitt, G. A. J. (I965). In Biological Council Symposium on Agents Affecting Fertility, p. 43. [C. R. Austin and J. S. Perry, editors.] London: J. and A. Churchill Ltd.

Thompson, J. N., Howell, J. McC., Pitt, G. A. J. \& Houghton, C. I. (1965). Nature, Lond. $205,1006$. Wolbach, S. B. \& Howe, P. R. (1928). Archs Path. 5, 239.

\section{EXPLANATION OF PLATES}

Plate I

Photomicrographs of sections of testis and epididymis of guinea-pigs that had been fed for 207 days on the vitamin A-free diet supplemented with either methyl retinoate or retinyl acetate. All are stained by haematoxylin and eosin.

(a) Testis of guinea-pig given retinyl acetate. The seminiferous epithelium and interstitial tissue are normal.

(b) Epididymis of guinea-pig given retinyl acetate. The epididymal duct is full of sperm.

(c) Testis of guinea-pig given methyl retinoate. Most of the germinal epithelium has been lost and many tubules do not have a lumen. There would appear to be an increased number of interstitial cells.

(d) Epididymis of guinea-pig given methyl retinoate. The epididymal duct does not contain sperm.

\section{Plate 2}

Photomicrographs of the retina of guinea-pigs that had been fed for 460 days on the vitamin A-free diet supplemented with either methyl retinoate or retinyl acetate, and of the bladder and trachea of vitamin A-deficient guinea-pigs. All are stained by haematoxylin and eosin. $A$, ganglion cell layer; $B$, outer cellular layer; $C$, inner cellular layer; $D$, rod and cone layer.

(a) Retina of guinea-pig given retinyl acetate. The structure is normal.

(b) Retina of guinea-pig given methyl retinoate. There is no evidence of the severe anatomical degeneration that would have been present in the retina of a rat maintained on such a regime.

(c) Tracheal epithelium of a guinea-pig that had been fed the vitamin A-deficient diet for 45 days. The epithelium to the left of the photograph is stratified squamous. The normal pseudostratified ciliated columnar epithelium is being replaced by stratified squamous type in the right half of the photograph.

(d) Bladder epithelium of a guinea-pig that had been fed the vitamin A-deficient diet for 39 days. The normal transitional epithelium has been replaced by a keratinized stratified squamous epithelium. 

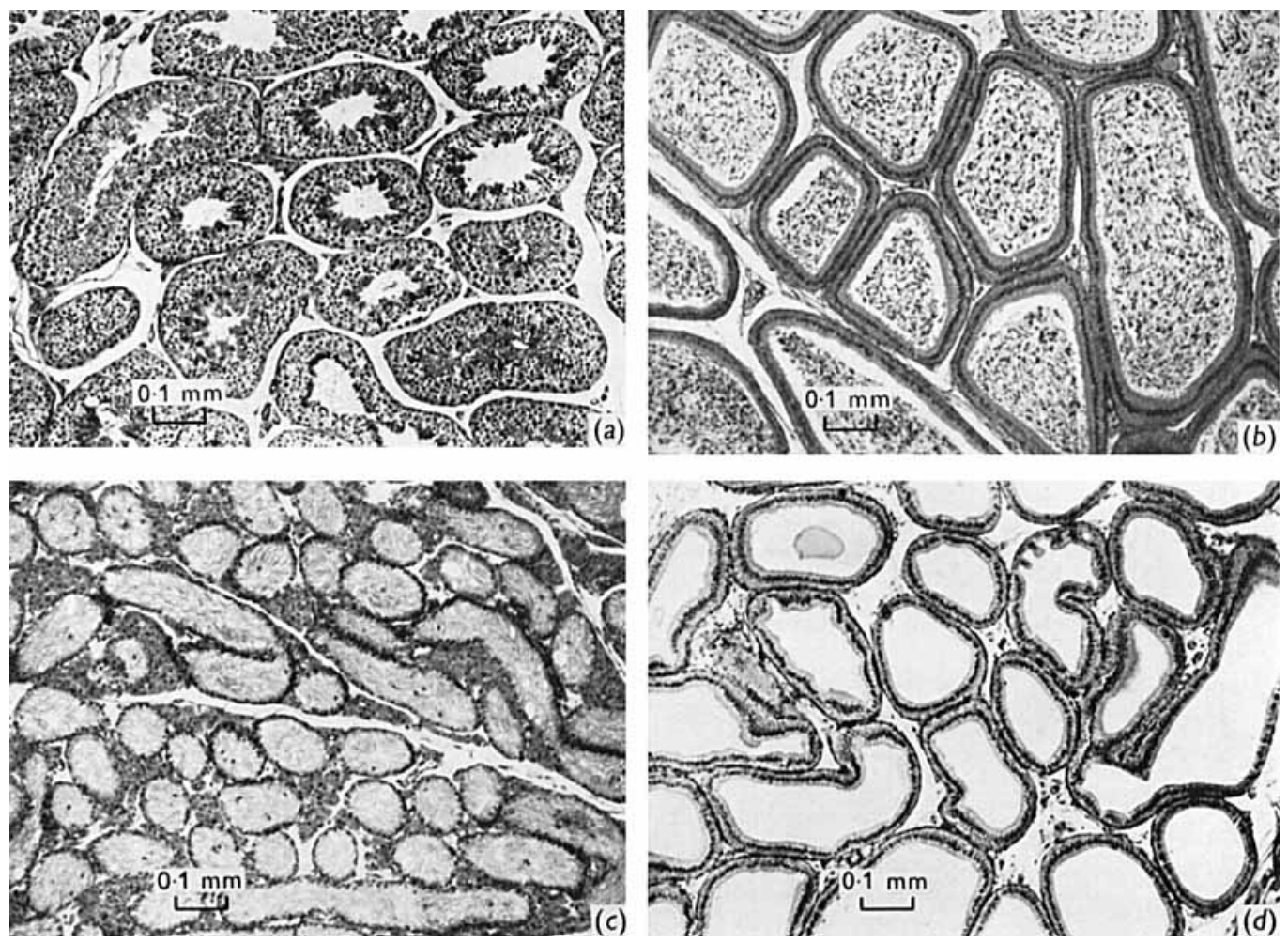
British Fournal of Nutrition, Vol. 21, No. I

Plate 2
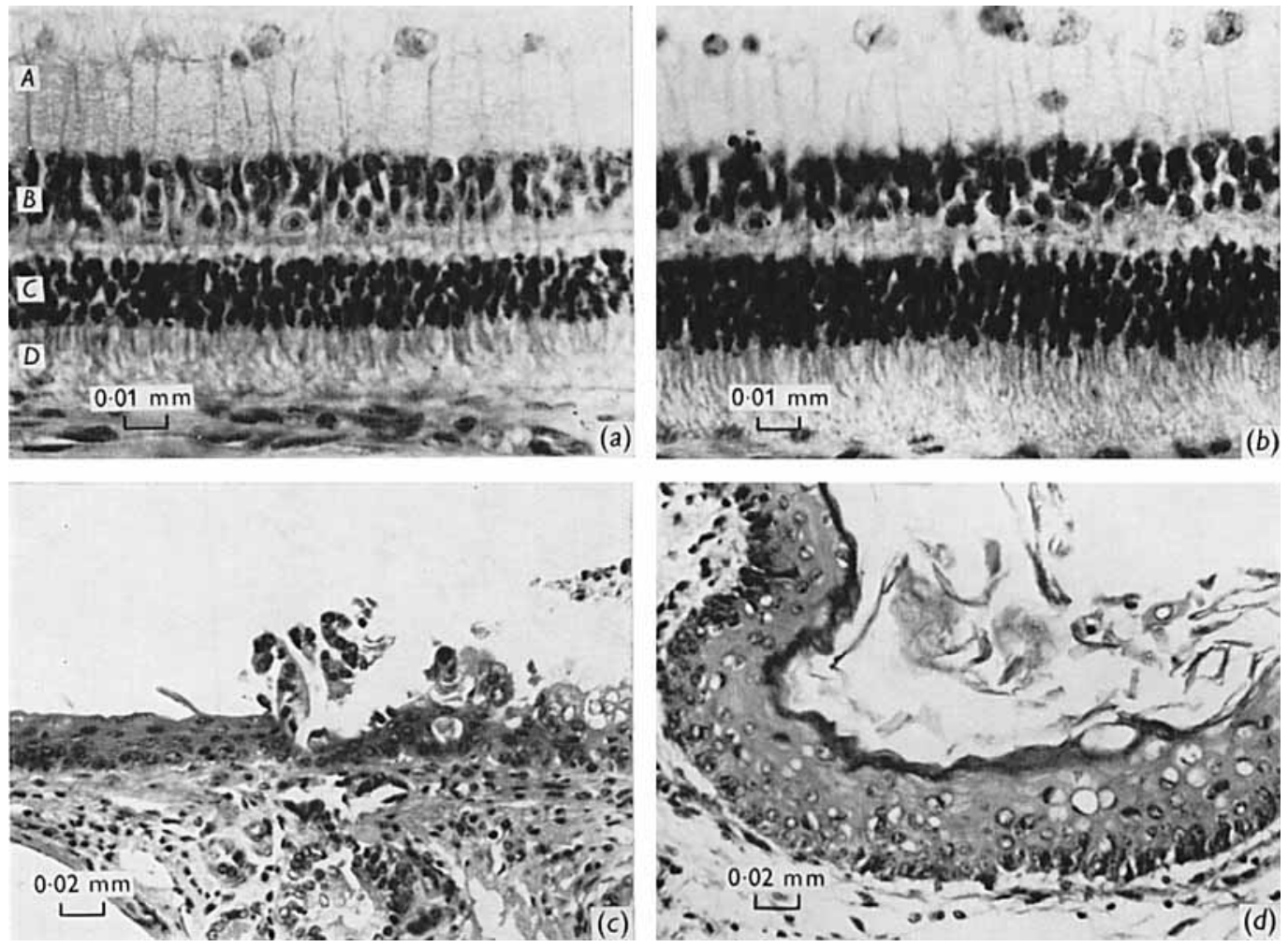

J. MCC. HOWELL, J. N. THOMPSON AND G. A. J. PITT 